\title{
AÇÃO INIBIDORA DO CEPA (ÁCIDO 2-CLOROETILFOSFÔNICO) SOBRE A GERMINAÇÃO DE SEMENTES DE Euphorbia heterophylla L.
}

\author{
Cecília N. K. Sudal \\ Jarbas F. Giorgini 2 \\ Antonio B. Gusman 2
}

\begin{abstract}
RESUMO - Euphorbia heterophylla L. (amendoim-bravo) é uma planta invasora de culturas anuais e perenes e ocorre principalmente em plantações de soja. As sementes de E. heterophylla foram classificadas em escuras e claras com base na coloração da testa. Ambos os tipos de sementes foram colocados para germinar em presença de Cepa em concentrações de 10, 100 E 1000 ppm. Foi verificado que o Cepa, nas três concentrações ensaiadas, inibiu a germinação de sementes escuras e claras de E. heterophylla. A cor da semente não tem influência sobre a porcentagem de germinação, tanto na presença como na ausência de Cepa, após 4 dias a partir do início da embebição.
\end{abstract}

Palavras-chave: Euphorbia heterophylla, Germinação de sementes, Ácido 2-Cloroetifosfônico, Planta invasora.

\begin{abstract}
Euphorbia heterophylla, L. is an important weed which occurs mainly in soybean fields. The seeds were grouped into dark and light, according to the seed coat color. Both types of the seeds were placed to germinate in solutions of 2-chloroethyphosphonic acid in the concentrations of 10,100 and $1000 \mathrm{ppm}$. The results showed a significant inhibition of grmination in the teste concentrations.
\end{abstract}

Key Words: Euphorbia heterophylla, Seed germination, 2-Chloroethylphosphonic acid, Weed.

\section{Introdução}

Euphorbia heterophylla L. (amendoim-bravo) ocorre em diversos países tropicais e subtropicais como planta invasora de várias culturas agrícolas (Wilson 1981). No Brasil essa espécie é de ampla distribuição (Lorenzi 1982) e há referências de ịnfestação de culturas de café (Blanco 1983), cana-de-açucar (Instituto Agronômico do Paraná 1977), milho (Gelmini 1982), algodão (Gelmini \& Cruz 1983) e notadamente soja (Guedes \& Wiles 1976; Cerdeira et al. 1981).

Segundo Wilson (1981), E. heterophylla é uma espécie de difícil controle, sendo resistente à maioria dos herbicidas utilizados na pré e pós-emergência. A recomendação de herbicidas específicos depende também do tipo de cultura. No Brasil, em culturas de milho, tem sido recomendado o uso do 2,4-D, enquanto que, em culturas de soja, o acifluorfen [(sódio 5-2 (cloro-4-trifluorometil)fenoxi]-2-nitrobenzoato) (Cerdeira et al. 1981).

O etileno pode promover, não afetar ou inibir a germinação de sementes de espécies invasoras (Bewley \& Black 1982; Egley 1982). Eplee (1975) sugeriu que o etileno pode ser utilizado na erradicação da espécie parasita Striga asiática, promovendo a germinação de suas sementes na ausência do hospedeiro (planta cultivada). A aplicação em potencial do etileno como um dos métodos de controle de outras espécies tem sido também realçada (Egley 1982).

As sementes de E. heterophylla são heterogêneas, podendo ser agrupadas segundo a coloração da testa (Bacchi et al. 1984; Gusman et al. 1986). As sementes escuras embebidas possuem um conteúdo menor de mucilagem e maior velocidade de germinação com relação às sementes mais claras (Gusman et al. 1986).

\footnotetext{
${ }^{1}$ Estudante do Curso de Licenciatura e Bacharelado em Ciências Biológicas.

${ }^{2}$ Departamento de Biologia, Faculdade de Filosofia, Ciências e Letras e Ribeirão Preto na Universidade de São Paulo. CEP. 14049. Ribeirão Preto, São Paulo.
} 
Neste trabalho, foi verificada a influência do CEPA sobre a germinação de sementes de E. heterophylla. Como parece que ocorrem diferenças fisiológicas entre os tipos de sementes desta espécie, foram utilizadas sementes escuras e claras em experimentos separados com a finalidade de verificar uma possível ação diferenciada do CEPA sobre cada um dos tipos de sementes desta espécie.

\section{Material e Métodos}

As sementes de E. heterophylla foram coletadas no Campo Experimental da Unesp, "campus" de Jaboticabal (SP) e armazenadas à temperatura ambiente ao abrigo da luminosidade.

As sementes foram classificadas com base na coloração da testa, em escuras e claras, sendo que as claras apresentaram diversas tonalidades da cor marrom.

Os experimentos de germinação foram realizados em placas de Petri contendo dupla camada de papel filtro. Foram utilizados um total de 50 sementes por placa, totalizando 200 sementes para cada tratamento (4 repetições). A cada placa foram adicionados $5,0 \mathrm{ml}$ de água destilada ou de solução de CEPA (50\%) a 10 ppm, 100 ppm ou 1000 ppm (convertendo à molaridade, as concentrações de CEPA são respectivamente 5,0 x $10^{-6}, 5,0 \times 10^{-5}$ e $5,0 \times 10^{-4} \mathrm{M}$. As placas foram transferidas para uma estufa a $30^{\circ} \mathrm{C}$, e o número de sementes germinadas avaliado a cada 12 horas, durante 4,5 dias.

Considerou-se a semente germinada quando a radícula emergente apresentou cerca de 2,0 mm de comprimento.

A análise estatística foi realizada utilizando-se o teste $\mathrm{F}$ associado ao teste de Tukey, ao nível de $5 \%$ de probabilidade.

\section{Resurtados e Discussão}

A curva de germinação das sementes escuras controles apresentou um padrão semelhante àquele relatado por Santos \& Corso (1986). Aparentemente, as sementes claras controles germinam mais lentamente que as escuras, sendo que a diferença de velocidade de germinação entre os dois tipos de sementes já foi relatada por Gusman et al. (1986).

As curvas de porcentagem de germinação acumuladas das sementes escuras (Figura 1A) e das sementes claras (Figura 1B) indicaram que as três concentrações de CEPA inibem a germinação das sementes durante o período de 4,5 dias a partir do início da embebição. A análise estatística realizada com os dados de 4,5 dias indicam que essa inibição não depende da coloração e nem da interação coloração-concentração de CEPA, sendo significativa apenas a influência da concentração. A concentracão de 1000 ppm foi a mais efetiva causando uma inibição da germinação de mais de $90 \%$, tanto das sementes escuras quanto das claras (Figura 2). A natureza da inibição causada pelo CEPA não foi determinada, entretanto, a concentração de $1000 \mathrm{ppm}$ pode ter sido tóxica para as sementes desta espécie e a concentração de 100 ppm, aparentemente, permitiu a recuperação de uma fração das sementes escuras indicando a possibilidade da ação do CEPA ser transitória (Figura 1A).

Tem sido demonstrado que o etileno promove a germinação de sementes de várias espécies de plantas invasoras (Egley 1982), entretanto, os resultados obtidos neste trabalho indicam que a germinação de E. heterophylla é inibida pelo CEPA. Estes resultados são consistentes com as conclusões de alguns autores que verificaram que o etileno pode inibir a germinação de sementes de algumas espécies de plantas (Olatoye \& Hall 1973; Taylorson 1979).

O significado do efeito do etileno nas sementes de E. heterophylla permanece obscuro. Provavelmente, o etileno age como um importante fator em condições naturais. Tem sido verificado que as sementes de E. heterophylla não germinam em locais relati- 
vamente profundos do solo (Bannon et al. 1978; Cerdeira \& Voll 1980; Machado Neto \& Pitelli 1980), portanto, possivelmente a compactação do solo nos locais profundos impede a livre difusão do gás e a concentração de etileno nestes locais pode ser suficiente para inibir a germinação dessa espécie.

Como o etileno possui ação inibitória sobre a germinação de sementes de E. heterophylla, experimentos de campo podem ser úteis para verificar a sua potencialidade como método de controle desta espécie.

\section{Agradecimentos}

A primeira autora agradece à Dra. Maria de Fátima A. Pereira, do Departamento de Fisiologia Vegetal da UNICAMP, pelas sugestões para análise dos dados e à colega Vilma P. de Almeida pelo auxílio na parte estatística.

\section{Referências Bibliográficas}

BACCHI, O.; LEITÃO FILHO, H. de F. \& ARANHA, C. 1984. Plantas invasoras de culturas. Campinas, UNICAMP. V.3.

BANNON, J. S.; BAKER, J. B. \& ROGERS, R.L. 1978. Germination of wild poinsettia (Euphorbia heterophyllla). Weed Sci., 26:221-225.

BEWLEY, J.D. \& BLACK, M. 1982. Physiology and Biochemistry of Seeds in Relation to Germination. Berlin, Springer - Verlag. V.2.

BLANCO, H. G. 1983. A importância do controle das ervas daninhas na cultura do café. Agroquimi. Ciba-Geigy 22.4-9.

CERDEIRA, A. L.; ROESSING, A. C. \& VOLL, E. 1981. Controle integrado de plantas daninhas em soja. Circ. Téc. EMBRAPA/CNPSO, Londrina, n: 4.

CERDEIRA, A. L. \& VOLL, E. 1980. Germinação e emergência do amendoim-bravo (Euphorbia heterophylla). In: CONGRESSO BRASILEIRO HERBICIDAS ERVAS DANINHAS, 13. Itabuna. Resumos..., p.26

EGLEY, G.H. 1982. Ethylene stimulation of weed seed germination. Agric. For. Bull. 5:13-18.

EPLLE, R.E. 1975. Ethylene: a witcheed seed germination stimulante. Weed Sci., 23:433-436.

GELMINI, G.A. 1982. Controle de plantas daninhas na cultura do milho Bol. Téc. Campinas, n. 158.

GELMINI, G. A. \& CRUZ, L.S.P. 1983. Controle de plantas daninhas na cultura do algodão. Bol. Téc. CATI, Campinas, n. 178.

GUEDES, L.V.M. \& WILES, T. L. 1976. O controle de ervas daninhas em plantio direto de soja no Paraná: avaliação em fazendas em escala comercial. In: SEMINÁRIO BRASILEIRO HERBICIDAS ERVAS DANINHAS, 11, Londrina. Resumos... p. 131.

GUSMAN, A. B.; MUCILLO, G.; GIORGINI, J. F. \& PITELLI, R. A. 1986. Estudos sobre a germinação das sementes de Euphorbia heterophylla. Plantas Daninhas (no prelo).

RECOMENDAÇÕES técnicas para a cultura da cana-de-açúcar no Estado do Paraná. 1977. Circular, IAPAR, Londrina. n. 6.

LORENZI, H. 1982. Plantas daninhas do Brasil: terrestre, aquáticas, Parasitas, tóxicas e medicinais. Nova Odessa.

MACHADO NETO, J. G. \& PITELLI, R. A. 1980. Efeitos da profundidade de semeadura na emergência de Euphorbia heterophylla. In: CONGRESSO BRASILEIRO 
HERBICIDAS ERVAS DANINHAS (13.), Itabuna, Resumos... p. 131.

OLATOYE, S. T.\& HALL, M.A. 1973. Interaction of ethylene and light on dormant weed seeds. In: Seed Ecology, London, Butterworths, p. 233-249.

SANTOS, D.M.M. dos \& CORSO, G.G. 1986. Germinação, pré-plantio, pré-emergência e pós-emergência de Euphorbia heterophylla L. (amendoim-bravo) sob a influência do diuron. In: CONGRESSO SOCIEDADE BOTÂNICA. 6., Anais... Campinas, p. 59-65.

TAYLORSON, R. B. 1979. Response of seeds to ethylene and related hydrocarbons, Weed Sci., 27:7-10.

WILSON, A. K. 1981. Euphorbia heterophylla: a review of distribution, importance and control. Trop. Pest Mgmt., 27:32-8. 


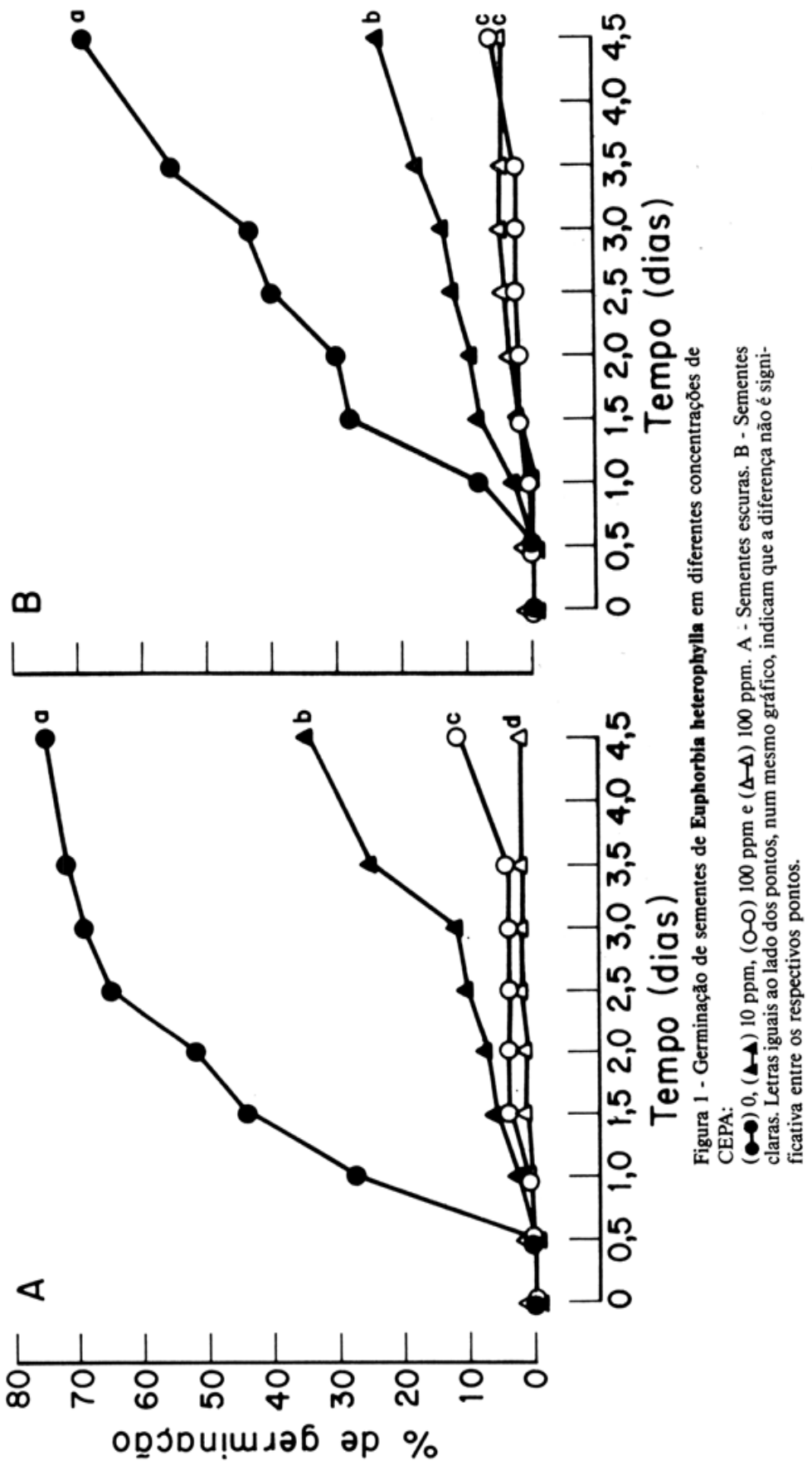




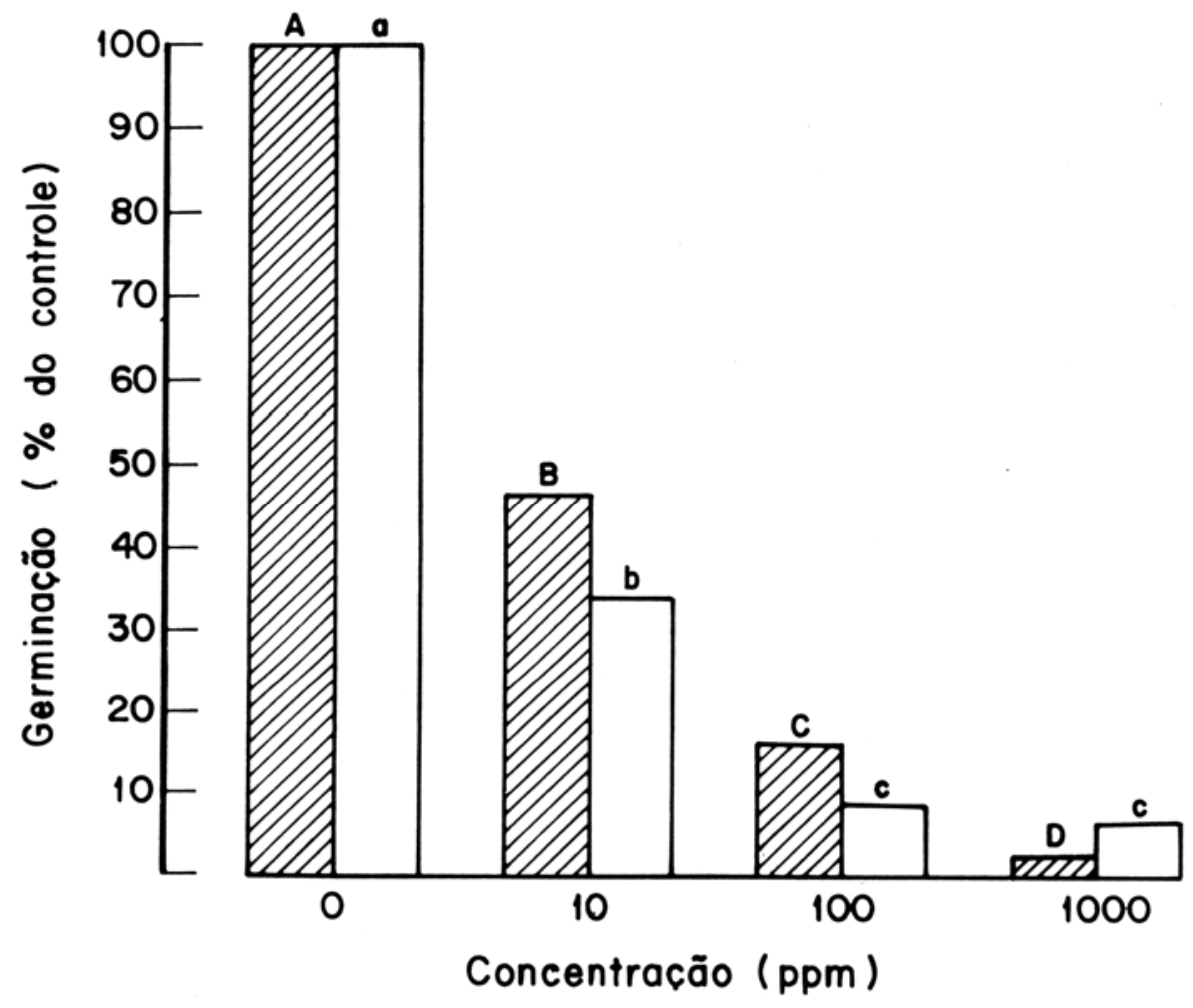

Figura 2. Efeito de diferentes concentrações de CEPA sobre a germinação de sementes escuras ( $\mathbb{Z}$ ) e claras ( $\square$ ) de Euphorbia heterophylla a 4,5 dias a partir do início da embebição. Letras iguais acima das colunas (maiúsculas comparam sementes escuras entre si e minúsculas, as claras) indicam que não há diferença significativa entre diferentes tratamentos com CEPA. 